\title{
ЗДОРОВЬЕ НАСЕЛЕНИЯ И ОКАЗАНИЕ СПЕЦИАЛИЗИРОВАННОЙ МЕДИЦИНСКОЙ ПОМОЩИ: РЕГИОНАЛЬНЫЙ АСПЕКТ
}

\author{
(c) 2019 Камашева Анастасия Васильевна \\ старший преподаватель кафедры управления человеческими ресурсами \\ Казанский (Приволжский) Федеральный Университет, Респ. Татарстан, Казань \\ E-mail: as112@list.ru \\ (C) 2019 Кузнецова Алсу Мунировна \\ старший преподаватель кафедры управления человеческими ресурсами \\ Казанский (Приволжский) Федеральный Университет, Респ. Татарстан, Казань \\ E-mail: alsu.legenda@gmail.com
}

Одним из важнейших показателей качества жизни населения страны являются показатели здоровья населения, при этом вопросы структуры оказания медицинской помощи, вопросы маршрутизации пациентов, а также подсчеты экономического ущерба от заболеваемости и смертности в разрезе отдельных заболеваний и регионов страны исследуются фрагментарно. В статье рассмотрены отдельные причины смертности населения трудоспособного возраста, динамика заболеваемости от новообразований, а так же рассмотрена система оказания специализированной медицинской помощи на примере одного из регионов.

Ключевые слова: здоровье населения, качество жизни населения, здравоохранение, причины смертности

Здоровье населения страны является важнейшим показателем качества жизни и социальноэкономического положения государства. Существует множество подходов оценки здоровья населения исходя из медико-статистических показателей, однако, связи между этими показателями, их динамикой и едиными рекомендациями для системы здравоохранения не существует как на уровне страны, так и на уровне регионов.

Несмотря на очевидную социальную значимость вопросов здоровья населения, широкого обсуждения данной темы в СМИ, оценка экономического бремени различных заболеваний и демографический ущерб исследуются фрагментарно. Это в первую очередь связано с отсутствием открытой информации о прямых затратах государства и граждан на лечение различных заболеваний, размерах затрат социального характера, а так же о потерях ВВП, связанных с заболеваемостью лиц трудоспособного населения.

Рассмотрим основные причины смертности населения России в трудоспособном возрасте, смертность от болезней системы кровообращения и внешних причин смертности стабильно снижается. Что же касается смертности от новообразований, и в том числе, от злокачественные новообразований (далее - ЗНО), ситуация остается стабильной.

Экономические потери от смертности рас-

считываются исходя из показателей бремени смертности (экономического ущерба, возникшего из-за одной смерти в определённом возрасте), зависящего от значения ВРП на одного занятого и уровня занятости населения, а так же количества смертей в определенном возрасте. Несмотря на социально-экономическую значимость данной проблемы мы нашли единичные работы, исследующие экономические потери от смертности в разрезе конкретных групп заболеваний и регионов страны. Растущее число больных злокачественными новообразованиями, негативная эмоциональная окраска восприятия заболевая, высокая смертность и тяжесть течения болезни и, а так же, значительные социальноэкономические потери общества, вызванные необходимостью обеспечить заболевших всем комплексом медицинских, реабилитационных и социально-экономических мероприятий традиционно поддерживают не проходящий интерес к проблеме совершенствования онкологической помощи населению [2].

В рамках государственных программ развития здравоохранения в последние годы уделялось особое внимание материально техническому оснащению медицинских учреждений современным диагностическим и лечебным оборудованием, но несмотря на очевидный прогресс в оснащении, результаты лечения по 
Таблица 1. Причины смертности в трудоспособном возрасте (умерших на 100000 лиц трудоспособного населения) [1]

\begin{tabular}{|l|c|c|c|c|c|}
\hline & 2012 & 2013 & 2014 & 2015 & 2016 \\
\hline $\begin{array}{l}\text { Причины смертности в трудоспособном возрасте } \\
\text { (умерших на 100000 лиц трудоспособного населения) }\end{array}$ & & & & & \\
\hline $\begin{array}{l}\text { Всего умерших от всех причин } \\
\text { Deaths from all causes }\end{array}$ & 575,7 & 560,9 & 565,6 & 546,7 & 525,3 \\
\hline $\begin{array}{l}\text { от болезней системы кровообращения } \\
\text { diseases of the circulatory system }\end{array}$ & 178,0 & 170,3 & 168,6 & 160,7 & 156,7 \\
\hline $\begin{array}{l}\text { от внешних причин смерти } \\
\text { ехternal causes оf тоrtality }\end{array}$ & 163,4 & 158,3 & 159,4 & 146,9 & 137,1 \\
\hline $\begin{array}{l}\text { от новообразований } \\
\text { пеорlasms }\end{array}$ & 82,7 & 81,9 & 79,9 & 80,5 & 78,9 \\
\hline $\begin{array}{l}\text { из них от злокачественных } \\
\text { оf them from таlignant (Соо-С97) }\end{array}$ & 81,6 & 80,8 & 78,9 & 79,4 & 77,9 \\
\hline $\begin{array}{l}\text { от болезней органов дыхания } \\
\text { diseases of the respiratory sуstem }\end{array}$ & 27,0 & 27,1 & 26,5 & 24,1 & 22,8 \\
\hline $\begin{array}{l}\text { от болезней органов пищеварения } \\
\text { diseases of the digestive sуstem }\end{array}$ & 47,0 & 45,5 & 50,1 & 50,6 & 47,5 \\
\hline
\end{tabular}

многим нозологическим формам злокачественных новообразований остаются неудовлетворительными. В значительной степени причиной этого является высокая доля больных, у которых злокачественное новообразование впервые выявлено на поздних стадиях заболевания [4]. Выявление и лечение злокачественных новообразований на ранних стадиях развития процесса обеспечивает в 75\% длительный и стойкий клинический эффект, в то время как выявление опухоли с обширным распространением практически в 100\% случаев исключает возможность получения стабильного клинического результата [5]. Еще в конце прошлого и начале нового веков рядом отечественных авторов отмечалось, что более $40 \%$ впервые выявленных больных имеют запущенные формы заболевания, когда возможности для радикального лечения ограничены [6].

Наблюдается стабильный рост заболеваемо- сти злокачественными новообразованиями, что может быть вызвано двумя основными факторами: реальным ростом заболеваемости, а так же повышением эффективности выявляемости заболевания, в том числе, в связи с внедрением диспансеризации. Основными целями работы здравоохранения по ЗНО являются снижение запущенности и снижение заболеваемости (по тем локализациям, где это возможно). К локализациям, где можно влиять на запущенность относят локации: молочная железа, шейка матки, предстательная железа, кожа, кишечник, рот и глотка, что в совокупности дает порядка 54\% всех случаев $3 \mathrm{HO}[8]$.

Задачами, которые должна решать организационная модель здравоохранения являются массовость - обеспечение максимального охвата населения силами первичной амбулаторной сети; и эффективность - выявление максимально возможного количества случаев $3 \mathrm{HO}$ на ран-

Таблица 2. Заболеваемость ЗНО в Российской Федерации 2005-2018 гг. [7]

\begin{tabular}{|l|c|c|c|c|c|c|}
\hline & 2005 & 2010 & 2015 & 2016 & 2017 & 2018 \\
\hline $\begin{array}{l}\text { Зарегистрировано заболеваний у пациентов } \\
\text { д диагнозом }\end{array}$ & 469,2 & 516,9 & 589,4 & 599,3 & 617,2 & 624,7 \\
\hline $\begin{array}{l}\text { Численность пациентов, } \\
\text { состоящих на учете в лечебно- } \\
\text { профилактических организациях }\end{array}$ & 2386,8 & 2794,2 & 3404,2 & 3518,8 & 3630,6 & 3762,2 \\
\hline $\begin{array}{l}\text { Из числа взятых на учет пациентов с диа- } \\
\text { гнозом злокачественного новообразования, } \\
\text { установленным впервые в жизни: }\end{array}$ & & & & & & \\
\hline имели IV стадию заболевания & 103,3 & 106,7 & 114,7 & 117,3 & 118,7 & 120,6 \\
\hline имели I-ІІ стадии заболевания & 29,6 & 39,7 & 81,5 & 92,1 & 106,4 & 115,4 \\
\hline выявлено при профилактических осмотрах & 52,1 & 63,5 & 110,1 & 118,8 & 139,6 & 148,1 \\
\hline
\end{tabular}


них стадиях

Для более детального изучения расстроим систему оказания онкологической помощи населению на примере Республики Татарстан.

Как видно из рисунка 1., динамика заболеваемости злокачественными новообразованиями в Республике Татарстан растет, темп роста в среднем по республике составляет 37,5\%, в то же время динамика роста заболеваемости отличается в зависимости от населенных пунктов и динамики старения населения. В рамках нашего исследования, мы вынесли отдельно динамику заболеваемости в столице республики и городе с населением более миллиона человек - Казани, и городе с максимальными в республике темпами роста заболеваемости - Набережные Челны.

На рисунке 2 представлена динамика смертности от злокачественных новообразований в разрезе республики и вышеперечисленных городов.

По нашим расчетам экономический ущерб от $3 \mathrm{HO}$ в Республике Татарстан за период 2013-2018 гг., рассчитанный на основе данных о смертности по причине злокачественных но-

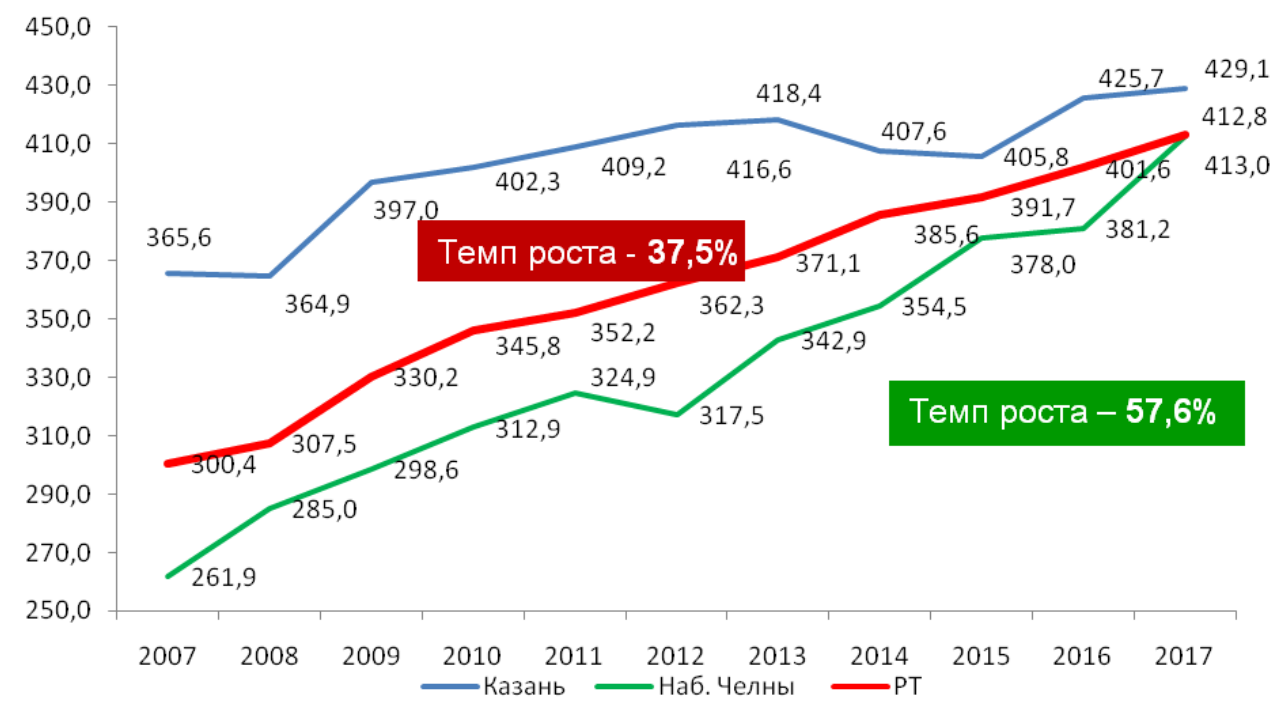

Puc. 1. Динамика заболеваемости ЗНО в Республике Татарстан, г. Казани и г. Набережные Челны за период 2007-2017 гг.

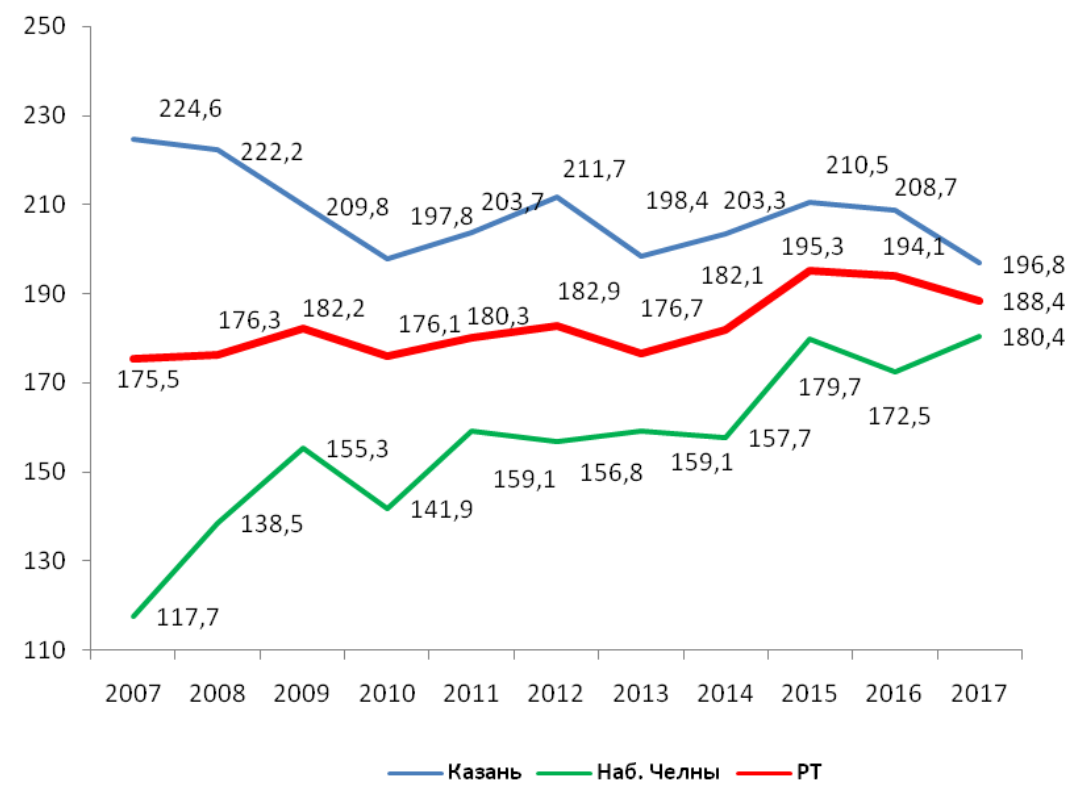

Puc. 2. Динамика смертности от ЗНО в Республике Татарстан, г. Казани и г. Набережные Челны за период 2007-2017 гг. 
вообразований и размером ВРП в расчете на одного занятого нарастающим итогом составляет более 100 млрд. руб.

Рассмотрим более подробно структуру службы оказания онкологической помощи. В республике функционирует трех уровневая система оказания медицинской помощи пациентам с онкологическими заболеваниями:

1. Первичные онкологические кабинеты

2. Межмуниципальные ПОО

3. ГАУЗ «РКОД МЗ РТ» и его филиалы

Первичные онкологические кабинеты были созданы на базе медицинских учреждений первичного звена, с целью увеличения доступности специализированной медицинской помощи, а так же снижения затрат времени пациента на диагностические мероприятия до установления диагноза.

На рисунке 3 представлены сведения о результативности работы первичных онкологических кабинетов, за последние годы доля лиц, направленных в специализированное учреждение колеблется в пределах $10-15 \%$ от общего числа осмотренных, что значительно снижает нагрузку на поликлиническое звено специализированной онкологической помощи в республике.

В тоже время нами выявлено достаточное количество проблем, связанных с взаимодействием внутри системы оказания медицинской помощи населению в республике по диагнозу новообразования, например:

- Дефекты маршрутизации, выявленные на этапе оформления первичных амбулаторных карт, выявляемые в процессе регистрации пациента в специализированном медицинском учреждении, что влечет значительную задержку по времени, а так же временные и транспортные затраты пациента. Например, врач ПОК не обследует пациента согласно требованиям Приложения № 4 Приказа МЗ РТ № 1970. Очень редко на руках у пациента при заведении амбулаторной карты в первичной регистратуре оказываются все необходимые обследования (анализы крови, инструментальные исследования). Либо результаты обследований оставляют в амбулаторной карте по месту жительства. И почти в большинстве случаев вместо рентгена ОГК стоит печать или имеется копия ФЛг.

- Неравномерность загруженности основного учреждения и его филиалов, а так же неравномерность возможности записи на первичный прием.

- Отсутствие единых стандартов и правил маршрутизации морфологических исследований.

- Сложности маршрутизации, возникающие у пациентов, которым диагноз новообразование под вопросом был поставлен в частных клиниках

- Большое количество пациентов попадают в головное учреждение «по связям», нарушая маршрутизацию пациентов.

Сложности в изучении проблематики здоровья населения и системы оказания помощи населению возникают из-за закрытости информации, необходимости междисциплинарного подхода к изучению проблемы, публикации укрупненных статистических данных, отсутствия регламентирующих документов с простроенной маршрутизацией пациентов.

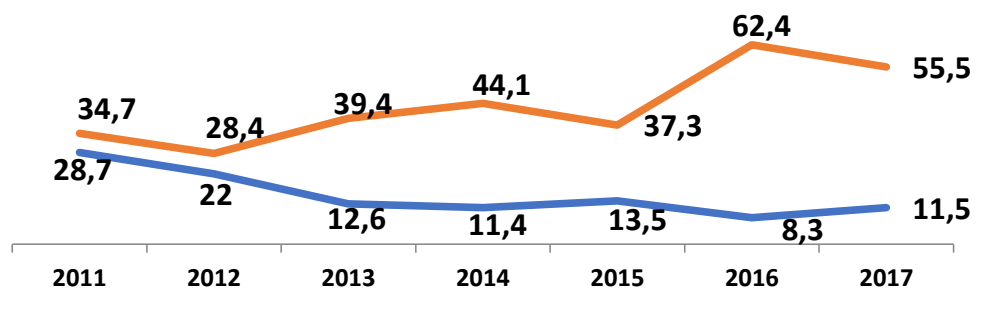

\begin{tabular}{|l|l|}
\hline $\begin{array}{c}\text { Доля лиц с подтвержденным диагнозом ЗНО от направленных в } \\
\text { ГАУЗ РКОД (\%) }\end{array}$ & $+27,7 \%$ \\
\hline $\begin{array}{c}\text { Доля лиц, направленных в ГАУЗ РКОД, от общего количества } \\
\text { осмотренных в ПОК (\%) }\end{array}$ & $-20,4 \%$ \\
\hline
\end{tabular}

Рис. 3. Результативность первичных онкологических кабинетов медицинских организаций 


\section{Библиографический список}

1. Демографический ежегодник России 2017 - Федеральная служба государственной статистики - https://gks. ru/bgd/regl/B17_16/Main.htm (режим доступа свободный)

2. Доможирова А.С. Комплексное применение профилактических технологий в онкологии на территориальном уровне: автореф. дис. ... д-ра мед. наук.- Челябинск, 2013. - 42 с.

3. Валеев Э.Р., Камашева А.В. Особенности состояния здоровья трудоспособного населения в Российской Федерации // Экономические науки - 2016 - № 12 - с. 50

4. Статистика здоровья населения и здравоохранения (по материалам Республики Татарстан за 2011-2015 годы): Вафин А.Ю., Шерпутовский В.Г., Шишмарева Е.И., Молокович Н.Н. [и др.].- Казань, 2016. - 268 с

5. Состояние онкологической помощи населению России / Под ред. А.Д. Каприна, В.В. Старинского, В.В. Петровой.- М.: ФГБУ «МНИОИ им. П.А. Герцена» Минздрава России, 2015.- 236 с.

6. Давыдов М.И., Аксель Е.М. Статистика злокачественных новообразований в России и странах СНГ в 2005 г. // Вестник Российского онкологического научного центра им. Н.Н. Блохина РАМН. - 2007.- Т. 18, № 2.C. 156.

7. Здравоохранение в России 2019 - Федеральная служба государственной статистики - https://gks.ru/bgd/ regl/b19_34/Main.htm (режим доступа свободный)

8. Ягудин Р.Х. Рыбкин Л.И. Состояние и динамика первичной заболеваемости взрослого населения Республики Татарстан // Дневник казанской медицинской школы - 2016 - № 2 - с. 57 